again asked to be kept informed as rapidly and completely as possible, so as to be able to respond to national information requirements in the same way as the international institutions-whether the ICRC or the League or both together-informed the international press in Geneva.

Some special questions were raised during the discussions. They included the commemoration of World Red Cross Day, relations with regional radio and television bodies, and the promotion of publications by the international Red Cross institutions and their dissemination in the world.

\title{
FIFTH INTERNATIONAL FESTIVAL OF RED CROSS AND HEALTH FILMS
}

The biennial Festival was an occasion to see the best films dealing with the Red Cross and questions of health which National Societies, film companies, universities, research institutes, health organizations and television had produced in recent years. ${ }^{1}$ It was held by the Bulgarian Red Cross at Varna from 18 to 27 June, under the patronage of the World Health Organization and the League of Red Cross Societies. ${ }^{2}$ This year there were 250 entries from forty countries.

The official closing ceremony, in Varna's spacious Palace of Sport and Culture, was presided over by Dr. Kiril Ignatov, President of the Bulgarian Red Cross, who had beside him Mr. José Barroso, Chairman of the League's Board of Governors. Also present were the Vice-Ministers of Public Health and National Education of Bulgaria and the Director-General of the Bulgarian Film Industry. The Festival awards were read out.

\footnotetext{
1 The Varna Festival was inscribed for the first time this year among the great world Film Festivals, by reason of its recognition by the International Federation of Film Producers' Associations and the International Film and Television Council.

- Plate.
} 
In the category of Red Cross films, the Grand Prix offered by the President of the Bulgarian Red Cross was attributed to a recent co-production of the League of Red Cross Societies, the Bulgarian Red Cross and the Hungarian Red Cross, Blood is Red all over the World, produced by Dr. Georgy Karpati (Hungary).

The League Grand Prix was awarded to the film Good Deeds of the Alliance of Red Cross and Red Crescent Societies of the USSR. In the category of short and medium length films on medical and health subjects, the Grand Prix of the President of the Bulgarian Red Cross was attributed to the film To be a Nurse (France). For feature fiction films, the Grand Prix of the President of the Committee of Art and Culture was awarded to the film Search for the Man (USSR), the Gold Medal to Family Life (United Kingdom) and the Silver Medal to Love (Hungary).

In the category of television films on medical and health subjects, the Grand Prix of the Director of Bulgarian Television was awarded to Rhesus Factor (Yugoslavia). Finally, in the category of scientific and educational films of a medical character, the Grand Prix of the Bulgarian Minister of Public Health went to Techniques of Laparoscopy (Federal Republic of Germany), the Gold Medal to Use of Laser Rays in Medicine (USA) and the Silver Medal to Implanting a New Urethra in Children (Poland).

Gold and silver medals as well as special prizes and diplomas of honour were attributed to twenty-one other films.

In the category of Red Cross films, a special diploma of honour was awarded to the film $P a x$, presented by the ICRC, owing to its originality and in recognition of the International Committee's work in the sphere of international humanitarian law 